\title{
Workplace Neighborhoods, Walking, Physical Activity, Weight Status, and Perceived Health
}

\section{Citation}

Forsyth, Ann, and J. Oakes. 2014. "Workplace Neighborhoods, Walking, Physical Activity, Weight Status, and Perceived Health." Transportation Research Record: Journal of the Transportation Research Board 2452 (December): 98-104. doi:10.3141/2452-12.

\section{Published Version}

doi:10.3141/2452-12

\section{Permanent link}

http://nrs.harvard.edu/urn-3:HUL.InstRepos:23680445

\section{Terms of Use}

This article was downloaded from Harvard University's DASH repository, and is made available under the terms and conditions applicable to Open Access Policy Articles, as set forth at http:// nrs.harvard.edu/urn-3:HUL.InstRepos:dash.current.terms-of-use\#OAP

\section{Share Your Story}

The Harvard community has made this article openly available.

Please share how this access benefits you. Submit a story.

Accessibility 
WORKPLACE NEIGHBORHOODS, WALKING, PHYSICAL ACTIVITY, WEIGHT STATUS, AND PERCEIVED HEALTH: ASSESSING THE BUILT ENVIRONMENT

\author{
Ann Forsyth, PhD (Corresponding Author) \\ Department of Urban Planning and Design \\ Harvard University \\ 48 Quincy Street \\ Cambridge, MA 02138 \\ Phone: 617-496-3587 \\ Fax: 617-496-1292 \\ aforsyth@gsd.harvard.edu \\ At time of research: \\ University of Minnesota \\ Minneapolis, MN 55454 \\ J. Michael Oakes, PhD \\ Division of Epidemiology and Community Health \\ School of Public Health, University of Minnesota \\ West Bank Office Building \\ 1300 S. Second Street, Suite 300 \\ Minneapolis, MN 55454-1015 \\ Phone: 612-624-6855 \\ Oakes007@umn.edu
}

Word count: 4760 (3510 words +4 tables +1 figure)

Date: February 24, 2014 


\begin{abstract}
Recent interest has focused on how the residential neighborhood built environment affects walking and other physical activity. The workplace neighborhood has been examined far less. This paper explores the neighborhood around the workplace in relation to walking, physical activity, body mass index, and perceived health for those who: (a) worked away from home $(\mathrm{N}=446)$ and $(\mathrm{b})$ were retired or unemployed $(\mathrm{N}=207)$. Study participants from the MinneapolisSt. Paul metropolitan area were recruited from environmentally diverse residential neighborhoods in 2004. They wore an accelerometer, kept a travel diary, and answered a survey. Their workplace neighborhood environments were measured using a geographic information system. In bivariate assessments, many features of the workplace neighborhood environment were significantly, but modestly, correlated with travel walking including density, street pattern, and land use (commercial, office, and residential). Fewer environmental features were correlated with total physical activity, a result confirmed in multivariate analyses. While several workplace neighborhood environmental variables were correlated with total walking, relevant to the field of transportation, the pattern of association with total physical activity was not as consistent or strong. Since many spend considerable time at work, more research is clearly needed on this topic.
\end{abstract}




\section{INTRODUCTION}

Recently several studies have examined how the home and school neighborhood built environment is associated walking and other physical activities. This paper uses data from a study in the Minneapolis-St. Paul area in Minnesota to explore a different kind of neighborhood environment, that around the workplace, and its correlation with walking, physical activity, body mass index, and perceived health. It draws on data from two groups of study participants, those who (a) worked away from home $(\mathrm{N}=446)$ and $(\mathrm{b})$ were retired or unemployed $(\mathrm{N}=207)$.

Work environments include the immediate vicinity of an individual's work activity, the interiors and immediate surroundings of workplace buildings, and the neighborhood in which a workplace is located. Such environments can be as small as a one-person office and as large as a farm. People are active while actually performing their paid work, while getting around buildings and grounds, and when moving around the neighborhood e.g. running errands, walking to parked cars, engaging in recreational activities during breaks, or connecting with transit service (1).

Workplace buildings and policies have been the subject of a number of studies. Recent systematic reviews find that worksite interventions such as programs focused on exercise training, motivation, and active commuting can increase physical activity, particularly walking, though effects are often modest $(2,3,4)$. In contrast, the focus of this paper is the correlation of the environmental character of the workplace neighborhood with walking, physical activity, and other outcomes relevant to health.

In the past, most research in the broad areas of walking, neighborhood environments, and health has examined residential environments. A number of reviews of this work have been published recently $(5,6,7)$. These reviews typically point to some associations between travel walking and destinations or land use mix and more modest associations with such factors as sidewalks and connectivity. Recreational walking has modest associations with recreational destinations and aesthetics of routes (5).

In terms of walking and transportation, a major focus has been on walking to work (commuting), both as active transportation alone and in association with transit trips (e.g. 11). Others have examined the association between environments and walking to school $(8,9,10)$. Some researchers have also explored walkability around the work place, for example developing audit tools (12).

Earlier studies looking at environments, health, and walking near the workplace are relatively rare but provide important background. Troped at al. (13) studied 1-kilometer buffers around homes and work places for 148 trail-users in Boston, monitoring activity with accelerometers and global positioning systems (GPS) mounted in backpacks. The study team examined five geographic information system (GIS) variables: intersection density, land use mix, population density, housing unit density, and a vegetation index. Both population and housing unit densities were positively associated with moderate and vigorous physical activity (MVPA) within the workplace neighborhood. Schwartz et al. (14) examined perceived worksite neighborhood environments, work site policies, and walking in Montgomery County, Maryland. They found no association between the perceived environment and self-reported walking above the median though there were some associations between the workplace neighborhood environment and whether participants walked at least once in a month. Several worksite 
policies were, however, associated with more weekday steps measured objectively. This current article adds to this prior work by using a larger sample and exploring more GIS-based environmental variables.

\section{DATA AND METHODS}

\section{Overall Study}

The Twin Cities Walking Study (TCWS) methods have been reported elsewhere $(15,16,17)$. Participants ( $\mathrm{N}=716 ; \mathrm{N}=700$ with work status data) were recruited in approximately equal numbers from $36805 * 805$ meter residential neighborhoods, selected for environmental diversity. Measurement was conducted in waves from April to November, 2004. Most (76\%) were randomly selected. Study demographics were roughly similar to those in the local area according to census data. Recruitment methods have been reported in detail (16). This paper examines two groups - those who worked away from home (the "AWAY" group) and the retired, unemployed, and absent ("NO WORK"). A group of those who worked at home ( $\mathrm{N}=47$ ) were excluded from analysis due to their small numbers. Figure 1 describes the residential locations or "focus areas" from which participants were recruited as well as the municipalities where two or more participants with usable GIS addresses worked ( $N=340)$. An additional 13 municipalities had only one worker.

\section{Measures}

Research staff measured participant heights and weights. Participants wore accelerometers and kept travel diaries for a week. They answered survey questions over the phone, including the International Physical Activity Questionnaire (IPAQ) long form for the last seven days, with a copy of the survey in front of them (18). Reported reliabilities for elements used in this paper (demographic and physical activity parts of the survey and the accelerometer measures) were excellent with the exception of the IPAQ which had low reliability and is used sparingly in this analysis $(16,19)$.

Work status was assessed in the following manner. Participants were asked: "Last week, did you do any work for pay?" If they answered yes they were classed as a worker and if not they were retired, unemployed, or absent from work: 190 were retired or unemployed and 17 temporarily absent. A second question asked how far they traveled to work-if it was 0 then they worked at home. This was cross checked with three other questions about the address of their primary work place, how many minutes it took to get to work, and how often they worked from home.

In the main study GIS measures were conducted for home environments using existing, field-collected, and aerial photo interpreted data. In addition, a smaller number of measures were done for work environments. These used existing GIS data as the work sites were dispersed and new data collection was not cost effective (20). The specific variables measured for workplace neighborhoods are discussed in the results section but they generally covered population and housing density, connectivity, and land use mix measures. Similar variables had been found to be associated with walking for transportation in prior studies $(5,6,7,19)$. The 
GIS-based variables were measured at 200, 400, 800, and 1600 meters around work places using both straight line (circular) and street network buffers. The differing buffer sizes were chosen to represent the immediate workplace neighborhood area as well as the larger workplace neighborhood that people might traverse during the work day and getting to and from work e.g. accessing transit. Both circular and street network buffers were used to test the sensitivity of results to buffer geometries, an issue that had not received much attention (21).

\section{Statistical Analyses}

We compared the background characteristics (i.e., potential confounders) between the WORK and NO WORK groups. Chi-squared tests of homogeneity, and t-tests, provide a crude sense of balance in bivariate relationships. Pearson correlations between work environmental features and physical activity outcomes are presented. Multiple regression models examined associations adjusted for potential confounders including age, sex, race, education, marriage, home ownership, household size, and household income plus physical activity at work. Negative binomial regressions were fit for outcomes that were skewed (such as walking and physical activity), and ordinary least squares (OLS) for those that were more normally distributed (such as weight status and perceived health). Clustered standard errors were employed in all regression models because the participants had been located in 36 residential areas and were assumed to have features in common. All analyses were conducted in Stata12/SE.

\section{RESULTS}

The AWAY group and NO WORK groups are described in Table 1. While we focus here on work environments, Table 1 indicates that the home neighborhood environments of participants were fairly evenly spread across the four types of residential areas from which participants were originally sampled. That is their home environments were not significantly different and thus results are not biased by the two groups living in very different kinds of places. Gender did not differ among groups. Data not reported here showed that levels of random sampling selection were not significantly different between the groups.

The two groups had roughly similar amounts of travel, leisure, and total walking measured by dairy, and their BMIs were similar, but those working were more active overall as measured by accelerometer and also perceived themselves as healthier. However, as can also be seen in Table 1, many social and demographic characteristics differed between the WORK and NO WORK groups. These included race, education, age, household income, car ownership, age, and years at one's home.

In data only pertaining to workers, and thus not reported in the table, the main commute mode to work in the previous week was driving (94\%) with bus, walking, and cycling each being used by $1-2 \%$ of respondents. That is very few were walking to work, but presumably more walked in the workplace neighborhood environment. Of those working away from home, only $20 \%$ were part time as opposed to full time or holding multiple jobs.

Table 2 uses data from the workplace neighborhood environments of 340 of the 446 people who worked away from home. The 126 other workers did not have good addresses 
typically because they worked in a large campus-style complex. The table presents only those correlations that were statistically significant for the $\mathbf{8 0 0}$ meter buffers, though all were very modest in scale. Results were typically similar for other buffer sizes so to simplify interpretation we only present one of the sizes. Measures that had no statistically significant correlations are listed in the table notes.

The three workplace neighborhood density measures all had positive correlations with total walking (travel diary). Total walking was also correlated with all three connectivity measures; and total physical activity measured by accelerometer with access points (the number of roads crossing the boundary of the measurement geography, in this case buffers of various distances around work places). Finally we measured a large number of land use measures many of which had no correlations with these outcomes (see Table 2 notes). Total walking was correlated positively with percent commercial and office land and negatively with residential land in the workplace neighborhood. The most consistent patterns of correlation with total physical activity were that work environments with more residential land area had less walking/physical activity. However, areas with higher numbers of residences per hectare had more walking. This perhaps suggests more walking in higher density mixed use areas but not ones where lower density residential uses predominate-there would likely be fewer nearby destinations.

In addition we analyzed results for total walking and total physical activity using the IPAQ and the results were even more modest but are reported here because the IPAQ is much used in research on physical activity. There were no significant associations with total physical activity and only a couple with land use mix (percentage of land use in commercial and office uses). However, as we noted above, published reliability data from this study had assessed the IPAQ and accelerometers with the IPAQ less reliable $(16,19)$. The likely more reliable measures of walking and physical activity-travel diary and accelerometer-of course did find some associations, though in the case of the accelerometer measures of total physical activity these were modest.

In analyses reported in Tables 3 and 4, the study also explored the association between workplace neighborhood environments and a number of health-related outcomes: travel, leisure, and total walking (diary), total physical activity (accelerometer), BMI, and perceived health. We first examined crude associations with three work environmental variables, one from each domain, that had the highest values of significant correlations with: (a) physical activity and if there had been no correlation or a tie, then (b) travel walking. The three variables were housing units per hectare (density), number of access points (connectivity), and percent commercial land use (land use mix) (Model A). We then adjusted for socio-demographic characteristics including age, sex, race, education, marriage, home ownership, household size, and household income plus physical activity at work measured by the IPAQ (Model B). Finally we ran models also including population density and median block size of the home neighborhood environment, variables used to stratify study areas and areas where, while there was no overall difference between the WORK and NOWORK groups, there may be subtle individual differences among workers (Model $\mathrm{C}$ ).

The main associations between workplace environments and these outcomes were that housing unit density in the workplace neighborhood was significantly but modestly associated with travel and total walking; and percent commercial land use with total physical activity. 
These patterns held in all the models. None of the workplace neighborhood environment variables were meaningfully associated with $\mathrm{BMI}$ or perceived health. In contrast a number of socio-demographic variables-race, education, and income--achieved significance in the expected directions. That is the models show a modest effect of mixed use on physical activity and walking. Specifically this association is between respondent work places and commercial development for physical activity in general and between work places and higher housing desnities in terms of both travel and total walking.

\section{DISCUSSION AND POLICY IMPLICATIONS}

Work environments are certainly places where people spend a great deal of time and the neighborhood settings of such workplaces are important potential locations for walking-both for utilitarian purposes and for recreation. Having more walking in workplace neighborhoods (of interest in transportation) could logically contribute to increased overall physical activity (a key outcome for those concerned about health).

In this study, while many workplace neighborhood environmental variables were associated with total walking (although with very modest values), the pattern of association with total physical was not as consistent or strong. This highlights some of the complex relationships between walking (in total and around the workplace) and overall physical activity. Specifically while much time is spent at work people are active in other parts of their lives - at home, doing chores, doing exercise, while socializing--and in other settings. Even if people are very active in the workplace neighborhood it may not increase their total activity because they may decide to do less activity in other domains, and vice versa. In addition, workplace neighborhood environments may in fact have only a modest effect on total walking and physical activity-other factors such as personal preferences, policies, programs, interior environments, and the like may be more important in how much overall physical activity people undertake.

This study had a number of limitations. This is an observational design: we did not randomize any persons to work environments, which means any causal inferences require large assumptions. Second, there are concerns about measurement error. In 2004, GPS was a relatively new technology, and is still cumbersome to use, so we do not know where walking and physical activity occurred. The population was also generally white and middle class. Because of missing addresses we did not measure well those in campus-style work environments and excluded most of this group from the environmental analysis. The study did not explore workplace policies, programs, and pricing of alternatives to walking (e.g. the price of workplace parking), all of which were likely to influence walking in the workplace neighborhood. Where it did look at socio-demographic variables it found substantial differences between those who worked and those who did not.

On the other hand this study had a larger sample than in previous work and looked at more environmental variables. It also looked both at total walking and a number of other outcomes related to health including physical activity, BMI, and perceived health. By examining two groups of participants from fairly similar residential neighborhoods - those who worked away from home and those who were retired and unemployed-it aimed to assess the 
difference that workplace environments made. It also was able to look at differences among those who worked.

There are some suggestive findings about mixed use areas near the workplace and increased walking, akin to those in Troped et al. (13) and compatible with conventional wisdom about supports for travel walking (22). However, this study does not support claims of very strong physical workplace neighborhood effects on total physical activity or BMI/obesity.

If these findings are replicated in subsequent studies there are several policy implications. In particular reviews of worksite interventions find modest effects of various programs and incentives on physical activity, particularly walking $(2,3,4)$. An environment supporting walking could enhance the effects of such programs. Even if its contribution alone is not large it could be magnified by these other programs and incentives. Employers interested in worker health could choose to locate in more mixed use areas to reinforce such worksite programming. We cannot, however, conclude that campus-style environments should be avoided because we did not study enough of them. With appropriate programming such environments may well support recreational walking. Since many spend considerable time at work, more research is clearly needed on this topic. 


\section{ACKNOWLEDGEMENTS}

The data collection for this research was funded by a grant from the Active Living Research Program of the Robert Wood Johnson Foundation.

\section{REFERENCES}

1. Zimring, C., A. Joseph, G. Nicoll, and S. Tsepas. Influences of building and site design on physical activity: research and intervention opportunities. American Journal of Preventive Medicine Vol. 28, No. 2, Suppl. 2, 2005, pp. 186-193.

2. Abraham C., and E. Graham Rowe $\backslash$ Are worksite interventions effective in increasing physical activity? A systematic review and meta-analysis. Health Psychology Review, Vol. 3, No. 1, 2009, pp. 108-144.

3. Hutchinson A., and C. Wilson. Improving nutrition and physical activity in the workplace: a meta-analysis of intervention studies. Health Promotion International, Vol. 27, No. 2, 2011, pp. 238-249.

4. Vuillemin A., C. Rostami, L. Maes, E. Van Cauwenberghe, F. Van Lenthe, J. Brug, I. De Bourdeaudhuij, and J.-M. Opert. Worksite physical activity interventions and obesity: A review of European studies. Obesity Facts, Vol. 4, 2011, pp. 479-488.

5. Sugiyama T., M. Neuhaus, R. Cole, B. Giles-Corti, and N. Owen. Destination and route attributes associated with adults' walking: a review. Medicine and Science in Sports \& Exercise, Vol. 44, No. 7, 2012, pp. 1275-1286.

6. Durand C.P., M. Andalib, G.F. Dunton, J. Wolch, and M.A. Pentz. A systematic review of built environment factors relates to physical activity and obesity risk: implications for smart growth urban planning. Obesity Reviews, Vol. 12, 2011, pp. e173-e182.

7. Wanner M., T. Gotschi, E. Martin-Diener, S. Kahlmeier, and B. Martin. Active transport, physical activity, and body weight in adults: a systematic review. American Journal of Preventive Medicine, Vol. 42, No. 5, 2012, pp. 493-502.

8. Lee B., P. Gordon, J.E. Moore, and H.E. Richardson. The attributes of residence/workplace areas and transit commuting. Journal of Transport and Land Use, Vol. 4, No. 3, 2011, pp. 43-63.

9. Lee M.C., M.R. Orenstein, and M.J. Richardson. Systematic review of active commuting to school and children's physical activity and weight. Journal of Physical Activity Health, Vol. 5, No. 6, 2008, pp. 930-949.

10. Faulkner G.E., R.N. Buliung, P.K. Flora, and C. Fusco. Active school transport, physical activity levels and body weight of children and youth: a systematic review. Preventive Medicine, Vol. 48, No. 1, 2009, pp. 3-8.

11. Lubans D.R., C.A. Boreham, P. Kelly P, and C.E. Foster. The relationship between active travel to school and health-related fitness in children and adolescents: a systematic review. International Journal of Behavioral Nutrition and Physical Activity, Vol. 8, No. 1, 2011, pp. 5. 
12. Dannenberg, A.L., T.W. Cramer, and C.J. Gibson. Assessing the walkability of the workplace: A new audit tool. American Journal of Health Promotion Vol. 20, No. 1, 2005, pp. 39-44.

13. Troped P.J., J.S. Wilson, C.E. Matthews., E.K. Cromley, and S.J. Melly. The built environment and location-based physical activity. American Journal of Preventive Medicine, Vol. 38, No. 4, 2010, pp. 429-438.

14. Schwartz M.A., S. Aytur, K.R. Evenson, and D.A. Rodríguez. Are perceptions about worksite neighborhoods and policies associated with walking? American Journal of Health Promotion Vol. 24, No. 2, 2009, pp. 146-151.

15. Forsyth A., M. Hearst, J.M. Oakes., and K.H. Schmitz. Design and destinations: factors influencing walking and total physical activity. Urban Studies, Vol. 45, No. 9, 2008, pp. 1973-1996.

16. Forsyth A., J.M. Oakes, and K.H. Schmitz. Test-retest reliability of the Twin Cities Walking Survey. Journal of Physical Activity Health, Vol. 6, No. 1, 2009, pp. 119-131.

17. Oakes J.M., A. Forsyth, M. Hearst, and K.H. Schmitz. 2009. Recruiting a representative sample for neighborhood effects research: strategies and outcomes of the Twin Cities Walking Study. Environment and Behavior, Vol. 41, No. 6, 2009, pp. 787-805.

18. Twin Cities Walking Study. Twin cities walking survey, 2004. http://www.activelivingresearch.org/index.php/Twin Cities Walking Survey/328

19. Sirard J., A. Forsyth, J.M. Oakes, and K.H. Schmitz. Accelerometer test-retest reliability by data processing algorithms: results From the Twin Cities Walking Study. Journal of Physical Activity Health, Vol. 8, 2011, pp. $668-674$.

20. Forsyth A., editor. Environment and Physical Activity: GIS Protocols. Version 3.0, 2005. http://www.designforhealth.net/resources/gis protocols.html

21. Forsyth A., D. Van Riper, N. Larson, M. Wall, and D. Neumark-Sztainer. Creating a replicable, cross-platform buffering technique: the sausage network buffer for measuring food and physical activity built environments. International Journal of Health Geographics. Vol. 11, No. 14, 2012, http://www.ij-healthgeographics.com/content/11/1/14.

12. Ewing R., and R. Cervero. Travel and the built environment: a meta-analysis. Journal of the American Planning Association Vol. 76, No. 3, 2010, pp. 265-294. 


\section{LIST OF TABLE TITLES AND FIGURE CAPTIONS}

FIGURE 1 Locations of Areas from which Participants were Recruited and Municipalities with Two of More Workers in the Minneapolis-Saint Paul Area.

Participants were recruited from environmentally diverse residential areas in a sector from the core city to the outer suburbs where particularly rich GIS data were available (right side). They worked in a greater variety of locations in the metropolitan area (left side).

TABLE 1 Comparison of Those Working Away from Home and those Retired, Unemployed, or Absent from Work

TABLE 2: Statistically Significant Correlations Between Neighborhood Work Environments, Walking, and Total Physical Activity

TABLE 3: Effects on Health Related Outcomes of Neighborhood Work Environment for those Working Away from Home: Walking Measured By Diary

TABLE 4: Effects on Health Related Outcomes of Neighborhood Work Environment for those Working Away from Home: For Physical Activity, BMI, and Perceived Health 
FIGURE 1 Locations of Areas from which Participants were Recruited and Municipalities with Two of More Workers in the Minneapolis-Saint Paul Area.


Locations with 2 or more workers

Inset: Residential focus areas

Participants were recruited from environmentally diverse residential areas in a sector from the core city to the outer suburbs where particularly rich GIS data were available (right side). They worked in a greater variety of locations in the metropolitan area (left side). 
TABLE 1 Comparison of Those Working Away from Home and those Retired, Unemployed, or Absent from Work

\begin{tabular}{|c|c|c|c|c|c|c|}
\hline & \multicolumn{2}{|c|}{$\begin{array}{l}\text { A. Work Away From } \\
\text { Home }\end{array}$} & \multicolumn{2}{|c|}{$\begin{array}{l}\text { B. No Work (Retired/ } \\
\text { Unemployed) }\end{array}$} & \multicolumn{2}{|c|}{ A vs. $B$} \\
\hline & $N^{1}$ & $\begin{array}{l}\text { \%/Mean } \\
\text { (Std. Dev.) }\end{array}$ & $\mathbf{N}$ & $\begin{array}{l}\text { \%/Mean } \\
\text { (Std. Dev.) }\end{array}$ & $\begin{array}{r}\text { Test } \\
\text { Statistic } \\
\end{array}$ & $\begin{array}{c}\mathrm{p}- \\
\text { value }\end{array}$ \\
\hline Total & 446 & 67.99 & 210 & 32.01 & & \\
\hline Women & 287 & 64.93 & 132 & 63.77 & & \\
\hline Men & 154 & 34.84 & 75 & 36.23 & $\chi^{2}=0.57$ & 0.75 \\
\hline \multicolumn{7}{|l|}{$\begin{array}{l}\text { Neighborhood Sample } \\
\text { Characteristics }^{2}\end{array}$} \\
\hline High Density, Large Block & 114 & 25.62 & 57 & 27.67 & & \\
\hline Low Density, Large Block & 113 & 25.39 & 45 & 21.84 & & \\
\hline High Density, Small Block & 113 & 25.39 & 53 & 25.73 & & \\
\hline Low Density, Small Block & 105 & 23.60 & 51 & 24.76 & $\chi^{2}=0.78$ & 0.86 \\
\hline \multicolumn{7}{|l|}{ Physical Activity and Health } \\
\hline Travel Walk (miles/day, diary) & 444 & $0.45(0.92)$ & 206 & $0.46(0.89)$ & $t=0.53$ & 0.60 \\
\hline Leisure Walk (miles/day, diary) & 444 & $0.36(0.75)$ & 206 & $0.42(0.75)$ & $t=1.00$ & 0.32 \\
\hline Total Walk (miles/day, diary) & 444 & $5.67(8.53)$ & 206 & $6.15(8.21)$ & $t=1.02$ & 0.31 \\
\hline Accelerometer ( 1000 counts/day) & 442 & $233.00(99.83)$ & 206 & $199.05(100.18)$ & $t=-3.87$ & 0.00 \\
\hline Total PA (met minutes/day IPAQ) & 445 & $653.94(689.04)$ & 206 & $508.19(455.35)$ & $t=-3.26$ & 0.00 \\
\hline $\begin{array}{l}\text { Total Walking (met minutes/day } \\
\text { IPAQ) }^{3}\end{array}$ & 445 & $155.57(202.14)$ & 206 & $112.86(150.57)$ & $\mathrm{T}=3.08$ & 0.00 \\
\hline $\begin{array}{l}\text { PA at Work (met minutes/day } \\
\text { IPAQ) }\end{array}$ & 445 & $285.40(551.75)$ & 206 & Not Applic. & Not Applic. & \\
\hline Body Mass Index (range) & 432 & $28.24(6.43)$ & 198 & $28.95(6.71)$ & $t=1.08$ & 0.28 \\
\hline $\begin{array}{l}\text { Overall perceived health ( } 5 \text { is } \\
\text { excellent) }\end{array}$ & 443 & $3.76(0.84)$ & 207 & $3.42(1.03)$ & $\chi^{2}=32.67$ & 0.00 \\
\hline \multicolumn{7}{|l|}{ Demographics } \\
\hline Race (Caucasian) & 376 & 84.68 & 159 & 76.81 & $\chi^{2}=6.80$ & 0.01 \\
\hline College Degree & 232 & 52.252 & 55 & 26.57 & $\chi^{2}=36.95$ & 0 \\
\hline Married & 248 & 55.86 & 129 & 62.62 & $\chi^{2}=2.49$ & 0.11 \\
\hline Own Home & 340 & 76.58 & 144 & 70.24 & $\chi^{2}=3.37$ & 0.07 \\
\hline Age & 444 & $44.07(11.68)$ & 205 & 53.62 (15.99) & $t=8.62$ & 0.00 \\
\hline Household Income $(x \$ 1,000)$ & 410 & $60.26(28.71)$ & 183 & $41.56(29.38)$ & $t=-7.29$ & 0.00 \\
\hline Car Ownership & 430 & 96.85 & 177 & 86.34 & $\chi^{2}=26.56$ & 0.00 \\
\hline Housing tenure in years & 442 & 9.81 (9.59) & 207 & $17.99(16.75)$ & $t=7.78$ & 0.00 \\
\hline Household size & 441 & $2.70(1.42)$ & 207 & $2.58(1.60)$ & $t=-0.95$ & 0.34 \\
\hline
\end{tabular}

1. $\mathrm{N}$ for percentages is the number in that category; $\mathrm{N}$ for means is the total number answering the question.

2. Residential neighborhoods ( $805 * 805 \mathrm{~m}$ in area) were stratified by block size and density as these had previously been found the be associated with travel walking

3. Met minutes per day are a measure of energy expenditure by duration 
TABLE 2: Statistically Significant Correlations Between Neighborhood Work Environments, Walking, and Total Physical Activity ${ }^{1,2}$

\begin{tabular}{|c|c|c|c|c|c|}
\hline Variable & $\begin{array}{l}\text { Min } \\
\text { Value }\end{array}$ & $\begin{array}{l}\text { Max } \\
\text { Value }\end{array}$ & $\begin{array}{l}\text { Diary } \\
\text { Total } \\
\text { Walking } \\
\text { (distance) }\end{array}$ & $\begin{array}{l}\text { Mean accel. } \\
\text { count for } \\
\text { valid day }\end{array}$ & $\begin{array}{l}\text { Median } \\
\text { accel. count } \\
\text { for valid day }\end{array}$ \\
\hline \multicolumn{6}{|l|}{ DENSITY MEASURES } \\
\hline \multicolumn{6}{|c|}{ Population/ Land Area (ha) } \\
\hline $800 \mathrm{~m}$ network & 0 & 75 & 0.16 & & \\
\hline $800 m$ straight line & 0 & 64 & 0.16 & & \\
\hline \multicolumn{6}{|c|}{$\begin{array}{l}\text { Population/ Developed Land Area } \\
\text { (ha) }\end{array}$} \\
\hline $800 \mathrm{~m}$ network & 0 & 127 & 0.16 & & \\
\hline $800 \mathrm{~m}$ straight line & 0 & 114 & 0.17 & & \\
\hline \multicolumn{6}{|c|}{ Housing Units /Land Area (ha) } \\
\hline $800 m$ network & 0 & 40 & 0.24 & & \\
\hline $800 \mathrm{~m}$ straight line & 0 & 37 & 0.24 & & \\
\hline \multicolumn{6}{|c|}{ CONNECTIVITY MEASURES } \\
\hline \multicolumn{6}{|c|}{ Median Census Block Area (ha) } \\
\hline $800 \mathrm{~m}$ network & 1 & 51 & & & \\
\hline $800 \mathrm{~m}$ straight line & 1 & 51 & & & \\
\hline \multicolumn{6}{|c|}{ Number of Access Points ${ }^{3}$} \\
\hline $800 m$ network & 3 & 54 & 0.19 & 0.11 & \\
\hline $800 \mathrm{~m}$ straight line & 1 & 50 & 0.17 & 0.11 & \\
\hline \multicolumn{6}{|c|}{ Road Length / Area (m/Ha) } \\
\hline $800 \mathrm{~m}$ network & 30 & 172 & 0.20 & & \\
\hline $800 \mathrm{~m}$ straight line & 15 & 159 & 0.22 & & \\
\hline \multicolumn{6}{|c|}{ Median Perimeter of Block (m) } \\
\hline $800 \mathrm{~m}$ network & 380 & 3722 & -0.14 & & \\
\hline $800 \mathrm{~m}$ straight line & 437 & 2863 & -0.17 & & \\
\hline \multicolumn{6}{|c|}{ LAND USE MIX MEASURES } \\
\hline \multicolumn{6}{|c|}{ \%Parcel Area Commercial } \\
\hline $800 m$ network & 0 & $70 \%$ & 0.22 & 0.13 & 0.13 \\
\hline $800 \mathrm{~m}$ straight line & 0 & $58 \%$ & 0.19 & & \\
\hline \multicolumn{6}{|c|}{$\%$ Parcel Area in Office } \\
\hline $800 \mathrm{~m}$ network & 0 & $49 \%$ & 0.14 & & \\
\hline $800 m$ straight line & 0 & $35 \%$ & 0.17 & 0.13 & 0.14 \\
\hline \multicolumn{6}{|c|}{ \% Parcel Area in Residential } \\
\hline $800 \mathrm{~m}$ network & 0 & $90 \%$ & & -0.11 & -0.11 \\
\hline $800 \mathrm{~m}$ straight line & 0 & $88 \%$ & -0.12 & -0.12 & -0.13 \\
\hline
\end{tabular}

1. $p<=0.05$, Pearsons correlations. Empty cells were not significant at this level.

2. We tested $200,400,800$, and 1600 meter network and straight line buffers but only report $800 \mathrm{~m}$ buffers here. We also tested a number of variables with no significant associations: Herfindahl-Hirschman Index (HHI); Percentage of total parcel area in parks and recreation; Percentage of total parcel area in industrial land; and Percentage of total parcel area in tax exempt land (e.g. government and nonprofit buildings). The entropy index (a measure of absolute mix) had modest associations with total walking (diary) at only the $1600 \mathrm{~m}$ buffer size.

3. The number of streets that cross the boundary of the buffer, a measure of connectivity. 
TABLE 3: Effects on Health Related Outcomes of Neighborhood Work Environment for those Working Away from Home: Walking Measured By Diary

\begin{tabular}{|c|c|c|c|c|c|c|c|c|c|}
\hline \multirow{2}{*}{$\begin{array}{r}\text { Outcome } \\
\text { Model }\end{array}$} & \multicolumn{3}{|c|}{ Travel Walk (miles/day) } & \multicolumn{3}{|c|}{ Leisure Walk (miles/day) } & \multicolumn{3}{|c|}{ Total Walk (miles/day) } \\
\hline & $\mathrm{A}$ & B & $\mathrm{C}$ & A & B & $\mathrm{C}$ & A & B & $\mathrm{C}$ \\
\hline Sample size & 340 & 316 & 316 & 340 & 316 & 316 & 340 & 316 & 316 \\
\hline \multicolumn{10}{|c|}{ Work environment (800m network buffers) } \\
\hline Housing units/ha & $0.040 *$ & $0.042 *$ & $0.036 *$ & 0.004 & 0.011 & 0.007 & $0.026 *$ & $0.030^{*}$ & $0.025 *$ \\
\hline Access Points & 0.011 & 0.006 & 0.008 & 0.003 & -0.001 & -0.001 & 0.006 & 0.000 & 0.002 \\
\hline$\%$ Commercial & 1.292 & 1.439 & $1.457^{*}$ & 0.112 & 0.021 & 0.036 & 0.864 & 0.958 & 0.970 \\
\hline \multicolumn{10}{|c|}{ Controls for Confounders } \\
\hline Age & & -0.005 & -0.003 & & 0.015 & 0.017 & & 0.007 & 0.008 \\
\hline Gender (Male) & & -0.106 & -0.128 & & -0.126 & -0.122 & & -0.081 & -0.094 \\
\hline Race (White) & & 0.367 & 0.373 & & 1.116 & 1.130 & & $0.481 *$ & $0.491 *$ \\
\hline College Degree & & $0.628 *$ & $0.815^{*}$ & & 0.321 & 0.336 & & $0.528 *$ & $0.629 *$ \\
\hline Married & & -0.096 & -0.094 & & 0.306 & 0.302 & & 0.075 & 0.071 \\
\hline Own Home & & $\begin{array}{r}- \\
0.474^{*}\end{array}$ & -0.327 & & 0.603 & 0.637 & & -0.220 & -0.127 \\
\hline $\begin{array}{r}\text { Household } \\
\text { Income }(x \$ 1,000) \\
\end{array}$ & & 0.000 & -0.001 & & 0.002 & 0.003 & & 0.000 & 0.000 \\
\hline & & & & & - & - & & - & \\
\hline Household size & & -0.122 & -0.101 & & $0.231 *$ & $0.227^{*}$ & & $0.151^{*}$ & $-0.140 *$ \\
\hline PA at Work/ Day & & & & & - & - & & - & \\
\hline (IPAQ) & & -0.000 & -0.000 & & $0.001 *$ & $0.001 *$ & & $0.000 *$ & -0.000 \\
\hline \multicolumn{10}{|c|}{ Home Neighborhood (800m network buffer) } \\
\hline \multicolumn{10}{|l|}{ Median Census } \\
\hline Block Area & & & $0.000^{*}$ & & & 0.000 & & & 0.000 \\
\hline \multicolumn{10}{|l|}{ Population / Land } \\
\hline Area & & & $0.000 *$ & & & 0.000 & & & $0.000 *$ \\
\hline & & & - & - & - & & - & - & \\
\hline Constant & $-1.768 *$ & -1.375 & 2.594* & $1.190 *$ & $3.092^{*}$ & -3.413 & $0.795^{*}$ & $1.097^{*}$ & $-1.847 *$ \\
\hline
\end{tabular}

Effects for highly skewed walking outcomes are non-exponentiated coefficients from negative binomial regressions. All models account for clustering by 36 neighborhoods and use robust standard errors. 
TABLE 4: Effects on Health Related Outcomes of Neighborhood Work Environment for those Working Away from Home: For Physical Activity, BMI, and Perceived Health

\begin{tabular}{|c|c|c|c|c|c|c|c|c|c|}
\hline \multirow{2}{*}{$\begin{array}{r}\text { Outcome } \\
\text { Model }\end{array}$} & \multicolumn{3}{|c|}{$\begin{array}{c}\text { Total PA by Accelerometer } \\
\text { (mean counts/day) }\end{array}$} & \multicolumn{3}{|c|}{ BMI (measured) } & \multicolumn{3}{|c|}{$\begin{array}{l}\text { Overall Perceived Health } \\
\text { (Survey) }\end{array}$} \\
\hline & A & B & C & A & B & C & A & B & $\mathrm{C}$ \\
\hline Sample size & 340 & 316 & 316 & 330 & 308 & 308 & 339 & 315 & 315 \\
\hline \multicolumn{10}{|c|}{ Work environment ( $800 \mathrm{~m}$ network buffers) } \\
\hline Housing units/ha & -0.003 & 0.000 & -0.000 & -0.010 & -0.013 & -0.013 & -0.005 & -0.000 & 0.000 \\
\hline Access Points & 0.003 & 0.002 & 0.003 & 0.002 & 0.004 & 0.004 & -0.003 & -0.005 & -0.005 \\
\hline$\%$ Commercial & $0.315^{*}$ & $0.327^{*}$ & $0.324 *$ & -0.119 & 0.047 & 0.045 & 0.480 & 0.465 & 0.461 \\
\hline \multicolumn{10}{|c|}{ Controls for Confounders } \\
\hline Age & & -0.004 & -0.003 & & 0.007 & 0.007 & & 0.004 & 0.003 \\
\hline Gender (Male) & & $0.136 *$ & $0.134 *$ & & 0.072 & 0.069 & & $0.206 *$ & $0.209 *$ \\
\hline Race (White) & & $0.187^{*}$ & $0.190 *$ & & -0.214 & -0.207 & & $0.430 *$ & $0.422 *$ \\
\hline College Degree & & 0.069 & 0.074 & & -0.228 & -0.221 & & $0.430 *$ & 0.439* \\
\hline Married & & -0.039 & -0.040 & & 0.141 & 0.140 & & -0.209 & -0.216 \\
\hline Own Home & & 0.060 & 0.065 & & -0.010 & -0.005 & & -0.011 & 0.001 \\
\hline $\begin{array}{r}\text { Household Income } \\
(x \$ 1,000)\end{array}$ & & 0.002 & 0.002 & & $-0.007 *$ & $-0.007 *$ & & $0.005^{*}$ & $0.005^{*}$ \\
\hline Household size & & $-0.041 *$ & $-0.041 *$ & & 0.040 & 0.041 & & -0.003 & -0.001 \\
\hline $\begin{array}{r}\text { PA at Work/ Day } \\
\text { (IPAQ) }\end{array}$ & & $0.000 *$ & $0.000 *$ & & 0.000 & 0.000 & & $0.000 *$ & $0.000 *$ \\
\hline Home Neighborhoc & $(800 \mathrm{~m} \mathrm{n}$ & etwork bu & fer) & & & & & & \\
\hline $\begin{array}{r}\text { Median Census } \\
\text { Block Area }\end{array}$ & & & 0.000 & & & 0.000 & & & 0.000 \\
\hline $\begin{array}{r}\text { Population / Land } \\
\text { Area }\end{array}$ & & & 0.000 & & & 0.000 & & & 0.000 \\
\hline Constant & $12.265^{*}$ & $12.073^{*}$ & $12.025^{*}$ & $1.998^{*}$ & 2.165* & $2.057 *$ & $3.834 *$ & $2.752 *$ & $2.083 *$ \\
\hline
\end{tabular}

${ }^{*} \mathrm{p}<=0.05$

Effects for highly skewed physical activity outcomes are non-exponentiated coefficients from negative binomial regressions; effects for remaining outcomes are coefficients from linear regressions. All models account for clustering by 36 neighborhoods and use robust standard errors. 